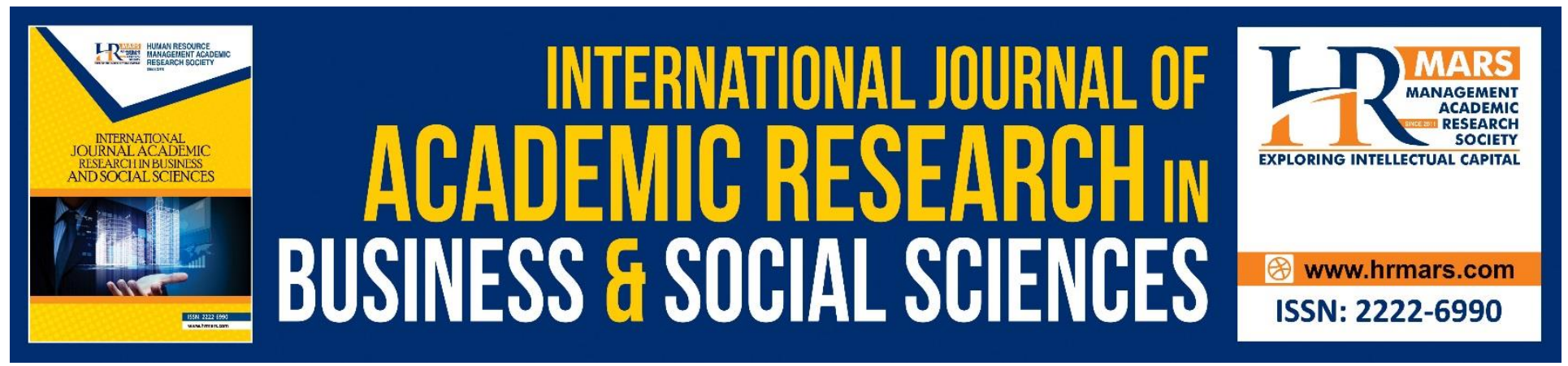

\title{
Coping Strategies as Predictors of Academic Achievement of the Left-Behind Children in Henan Province, China
}

\author{
Priyadarshini Muthukrishnan, Wang Xiani
}

To Link this Article: http://dx.doi.org/10.6007/IJARBSS/v9-i3/5759

DOI: $\quad 10.6007 /$ IJARBSS/v9-i3/5759

Received: 23 Feb 2019, Revised: 22 March 2019, Accepted: 30 March 2019

Published Online: 09 April 2019

In-Text Citation: (Muthukrishnan \& Xiani, 2019)

To Cite this Article: Muthukrishnan, P., \& Xiani, W. (2019). Coping Strategies as Predictors of Academic Achievement of the Left-Behind Children in Henan Province, China. International Journal of Academic Research in Business and Social Sciences, 9(3), 1028-1043.

Copyright: (C) 2019 The Author(s)

Published by Human Resource Management Academic Research Society (www.hrmars.com)

This article is published under the Creative Commons Attribution (CC BY 4.0) license. Anyone may reproduce, distribute, translate and create derivative works of this article (for both commercial and non-commercial purposes), subject to full attribution to the original publication and authors. The full terms of this license may be seen

at: $\underline{\text { http://creativecommons.org/licences/by/4.0/legalcode }}$

Vol. 9, No. 3, 2019, Pg. 1028 - 1043

http://hrmars.com/index.php/pages/detail/IJARBSS

JOURNAL HOMEPAGE

Full Terms \& Conditions of access and use can be found at http://hrmars.com/index.php/pages/detail/publication-ethics 


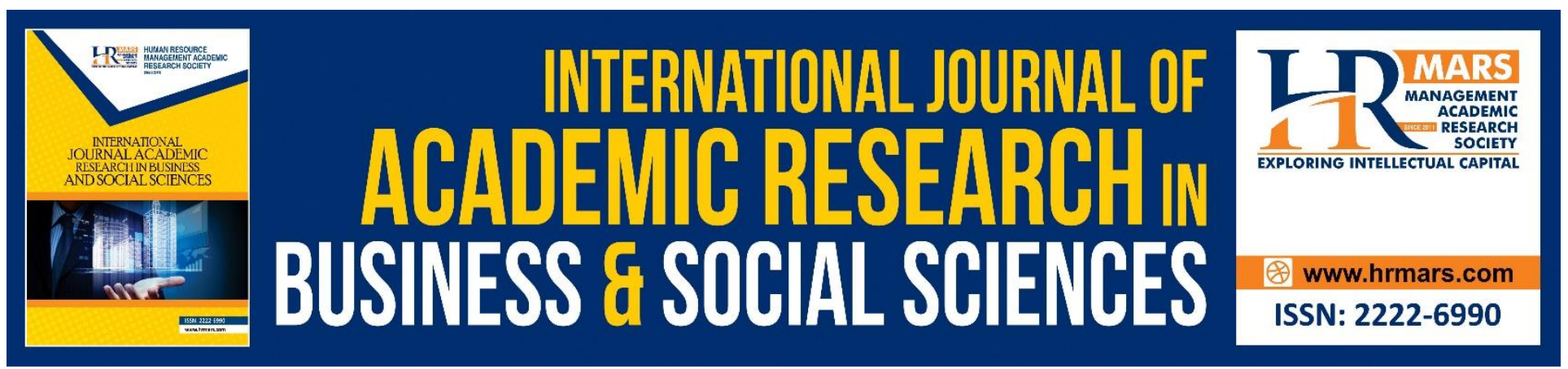

\title{
Coping Strategies as Predictors of Academic Achievement of the Left-Behind Children in Henan Province, China
}

\author{
Priyadarshini Muthukrishnan, Wang Xiani \\ Faculty of Education, SEGi University, Kota Damansara, Selangor, Malaysia
}

\begin{abstract}
With rapid development of economy in China, and the migration of the rural population to the industrialised area have caused the parents to leave behind their children with relatives or care takers. This has resulted in increased number of left-behind children in China. The current study investigated the impact of coping strategies on the academic achievement of the left behind children. The research adopted quantitative research methodology and data was collected from 186 left behind children in Henan Province, China. To investigate the different coping strategies adopted by the children, Children's Coping Strategies Checklist (Ayers, 1991) was used. Correlation and multiple regression analyses were conducted to examine the relationship between the various predictors and academic achievement. The findings concluded that coping strategies significantly correlated with academic achievement. The multiple regression model with all 11 predictors resulted in $R^{2}=30.2, F(11,174)=6.852, p<.001$. This concluded that $30.2 \%$ of the variance in achievement can be predicted by coping strategies. Problem focused support were identified as the significant predictors of academic achievement. Other coping strategies did not contribute to the multiple regression model.
\end{abstract}

Keywords: Coping Strategies, Academic Achievement, Coping, Left-Behind Children, China, Seeking Understanding, Problem Focussed Support, Cognitive Avoidance

\section{Introduction}

In China, the migration of the people from rural to urban areas has been increasing for over 35 years. Such population movements often lead to separation between family members, due to stringent entry polices, financial constraints, and limited access to public goods in the destination (Valtolina \& Colombo, 2012). This separation has raised concerns about the psychosocial wellbeing of children. When migrant parents leave their children behind in the care of others termed as left-behind children (LBC), usually grandparents or other relatives (Asis, 2006). Because their parents always stay away from their children, the LBC's personality, involvement at academics and their ability to face the 
stressful life events are at risks too. The current research has undertaken the coping strategies applied by these children in overcoming the stress and their coping adopt and influence their academic performance.

Children behavioral problems are the outcomes of children's psychological well-being and is a major concern towards children's development and functioning. The research findings on the psychological well-being of the children in 2011 showed that $20 \%$ of the children across the globe were affected by behavioral problems. (UNICEF, 2011). The consequences of behavioral problems among children result in the serious disruption of their motivation in academics, self- inquiry and mental health problems (Montague, Enders \& Castro, 2005; Marshall, Tilton-Weaver \& Statin, 2013).

\section{Literature Review}

\section{Migration and Left-behind children}

Different scholars in literature have used the term left-behind children in various contexts and there is no universally accepted definition for this special group of children. Ye and Murry (2005), termed left-behind children as those with one migrant parent either father or mother and the children are raised by the other parent along with their close relatives from the older generation. Other studies consider children with two migrant parents, where the children are cared by someone in the older generation (Fan et al., 2010). Migration negatively affects children in a variety of ways. It is inhibitory in to the child development, especially lesser parental involvement in raising their children result in weakened relationship between the migrant parent and the left-behind child. The link between family structures and child development have been documented by several researches that further show the academic, behavioural and emotional disadvantages that left-behind children face in the long run as compared to their peers in a two-parent household (McLanahan \& Sandefur, 1994; Wen, 2008). Some researchers find no significant difference between left-behind children and their peers in the aspect of academic interest and academic achievement, however, there exist noteworthy differences in the academic supervision and home environment (Lv, 2006). Children with migrant parents have increased labour burdens, affecting the amount of time and effort that they could spend on their schoolwork and studies at home. Moreover, they lack a family tutor to help them in any areas of misunderstanding or doubt in their academics Ye and Murray, 2005; Cao, 2007). Thus, academic performance of left-behind children lag behind in comparison to their own previous performance in the periods when their parents had not yet migrated.

Educational status of the left-behind children

The movement of rural labourers to urban areas in China is vitally different from the migration circumstances in other countries, because most of the labourers migrated to rural areas of China are not allowed to become permanent residents due to the population registration system. The household registration system in China has prevented migrants from enjoying the same welfare as the locals and they are not eligible for public housing and their children are not admitted into public schools within the city. Due to these difficulties and the high costs of childcare and schooling in cities, most parents leave their children back home under the care of relatives such as grandparents, aunts and uncles. China's one-child policy implemented in 1979 to control the country's population rate was so successful that the growth rate dropped significantly. Even as early as 1985 , about $80 \%$ to $90 \%$ of young couples in urban areas and $50 \%$ to $60 \%$ in rural areas had only one child (Tseng et al., 1988). 
This policy has very drastically altered the family structure, changing from favouring many children to just one. The family structure most common in recent times has a ratio of 4:2:1-four grandparents, two parents and one child, meaning the child is the only hope within the family. Great expectations are placed upon the children, mostly in the academic aspects of the child since it is critically associated with success in the increasingly competitive world. Grandparents remain to be important care givers within the family, especially during the youth of their grandchildren or when their own children have migrated to other areas for better employment opportunities and financial stability.

\section{Coping and Achievement}

Several studies have pointed out that the educational aspirations of the LBC are low and that has resulted in dropouts from school and low percentage of the children completing their compulsory education (Koo, Ming \& Tsang, 2014; UNICEF, 2014).Given that the importance of education is the key to lift one's own living to better standards, the life events that allows LBC to continue, complete and excel in their education despite these challenges is the need of the hour. Studies indicated that depressed children are more likely to perform poor in academics later in life. This has raised a high risk of loss of competent human capital due to the onset of early depression. Further, the associated behaviors of depression include crime, anti- social and deviant behaviors. Therefore, improving the mental health of the LBC will have a significant positive impact on reduction of crime and improved living, health and education of these children.

Coping strategies in the academic domain is referred as resilience, everyday resilience, or academic buoyancy, and is characterized as a set of resources a student can access to help them to be resilient after a setback or failure and to take part in the academic work. Taken together in its different forms, coping repertoire of behaviors can be adaptive, allowing for effective management of stressors and continued engagement with challenging situations, or maladaptive, leading to a state of helplessness and disaffection from academic challenges. Earlier findings confirmed that the nature of a child's coping profile, that is, the most common pattern of response to stressful academic circumstances, also exerts an influence on a student's level of engagement. Coping refers to the thoughts and behaviors that a person uses to manage the internal and external demands of stressful situations Folkman and Moskowitz (2004). It involves the conscious efforts placed on adjusting emotion, cognition, behavior and physiology in response to stress (Compas et al., 2001).

Research suggests that parental migration may also bring some positive aspects into the lives of leftbehind children. Children with migrant parents tend to have better overall economic advantages as compared to their peers due to the parent's better livelihoods in the urban areas. The migration from rural to urban areas often leads to a change of perception of the world, greater ambitions and modified outlooks of life, thus broadening the mind-sets of the migrant parents. This, in turn, affects their children who are supplied with new information that their parents provide them with during parent-child communication. Their parents' ideologies significantly affect the left behind children by deepening their passions and ambitions, providing a finely tuned awareness of the importance of education and fostering eagerness in working towards a better future for themselves. 


\section{Significance of the Study}

The research literature related to LBC and their physiological and psychological health problems have been well explored. Many studies have demonstrated that LBC suffer poor physical health (Shen et al., 2015), depression and anxiety problems (He et al., 2012; Zhao et al., 2014), smoking behaviors (Yang et al., 2016; Zhao et al., 2014), loneliness (Liu et al., 2010), poor academic performance (Gao et al., 2010), high risk behaviors and suicidal attempts (Gao et al., 2010), early drop outs from school (Gao et al., 2010), low self-esteem (Liu et al., 2010).

Although many studies have been carried out to demonstrate the social and behavioral problems associate with LBC in rural China, studies related to the impact of coping and coping strategies on the academic achievement of the $L B C$ in rural China still remains unclear. Particularly little is known about the coping and the means how the LBC encounter the stressful life situations. Furthermore, many studies have made comparative study of LBC and normal children or non-left-behind children (NLBC). The present study seeks to enhance our understanding of the relation of specific coping behaviors of the middle school left-behind children in San Men Xia, Henan Province, China. It improves upon previous research by addressing the type of coping strategies adopted by the LBC in overcoming the stressful life events, and their academic performance at school. To narrow this gap of knowledge in this research area, the present research was to determine the impact of coping on the academic achievement of the LBC in rural china. Furthermore, this study aims to add insights to the limited research on coping, coping strategies of the $L B C$ as they relate to academic achievement. This research will bring forth the recommendations and suggestions to improve the mental health of the LBC by planning appropriate intervention programmes that focus on teaching effective coping strategies to overcome stress, anxiety and depression of LBC. Therefore, the current research focused on the following research questions.

1) What is the level of coping of the LBC?

2) What is the level of academic achievement of the LBC?

3) Are there significant relationships between different coping strategies and academic achievement of the LBC?

4) What are the most significant coping strategies that predict the academic achievement of the LBC?

\section{Method}

The study used quantitative research methods to address the research questions. Survey questionnaires were used to collect data and SPSS $22.0 \mathrm{v}$ was used to analyse the data. The target population for the current research is the left-behind students with the age range between 12 to 15 years old and studying in grade 8 of the middle school, which are located at San Men Xia in Henan province, China. This study focus on the left-behind children, therefore the sample for the study includes only the left- behind children (LBC) studying in grade 8 in the selected schools of study at San Men Xia in Henan province. This research used probability-sampling technique to collect data from the LBC. There are 12 middle schools at San Men Xia in Henan Province and the study considered collecting data from the LBC in all the 12 middle schools. Data was collected from a sample of 200 left behind children from 12 schools using probability sampling technique. From each school, five 
classes were selected randomly and about 16-17 left behind children from each school were considered for the study.

\section{Research Instruments}

The research instruments used in the study consists of two parts. Part A of the questionnaire has the demographic variables of the participants and Part B is the survey questionnaire to measure the different coping strategies adopted by the left behind children. The present study adopted the questionnaire Children's coping strategies checklist (CCSC) developed by Ayers (1991). The questionnaire consists of 45 items, which are measured under eleven dimensions. These eleven dimensions represents the different coping strategies adopted by the children during stressful life events or situations. The eleven dimensions are cognitive decision making, direct problem solving, seeking understanding, positive cognitive restructuring, expressing feelings, physical release of emotion, distracting actions, avoidant actions, cognitive avoidance, problem focused support and emotion focused support. There are 4 items for cognitive decision making, 4 items for direct problem solving, 5 items for the seeking understanding, 4 items for positive cognitive restructuring, 3 items expressing feelings, 4 items for physical release of emotion, 5 items for distracting actions, 4 items for avoidant actions, 4 items for cognitive avoidance, 4 items for problem focused support and 4 items emotion focused support. All the items are positive and the students have to respond to the questionnaire on a five points Likert Scale which has the range of options from never to always. As for the all, the items we have already recoded in the data editing process. An expert translator translated the questionnaires to Mandarin. The reliability of the questionnaire was conducted and all reliability scores were above 0.85 . The translated questionnaires were than back translated to English to verify the content validity and construct validity of the Mandarin translated questionnaires.

\section{Findings}

\section{Descriptive of the Demographic Variables}

The following Table 1, illustrates the demographic profile of the participants with respect to gender, age group of the children, care takers of the children, mother's and father's education, annual income and their mother's and father's education.

Out of the total respondents, slightly more than half were girls. There were $52.2 \%$ of girl respondents while the rest $47.8 \%$ of the respondents were boys. While considering the distribution of sample based on the respondents' care takers, the results indicated that majority of the students which accounted for $64.5 \%$ are living in students' accommodation, $14.9 \%$ of them are living with their grandparents and $7.5 \%$ of them are residing with their relatives. 
INTERNATIONAL JOURNAL OF ACADEMIC RESEARCH IN BUSINESS AND SOCIAL SCIENCES

Vol. 9, No. 3, March, 2019, E-ISSN: 222 2-6990 @ 2019 HRMARS

Table1.

Distribution of Respondents by Demographic Variables

\begin{tabular}{lll}
\hline Demographic Variables & Frequency & Percent (\%) \\
\hline 1. Gender & Frequency & Percent (\%) \\
Boy & 89 & 47.8 \\
Girl & 97 & 52.2 \\
Total & 186 & 100.0 \\
\hline 2. Care Takers & Frequency & Percent (\%) \\
Grandparents & 52 & 14.9 \\
Students' accommodation & 120 & 64.5 \\
Relatives (Aunt/Uncle/Sibling) & 14 & 7.5 \\
Total & 186 & 100.0 \\
\hline
\end{tabular}

\section{Descriptive of Coping Strategies adopted by the LBC}

The level of coping was analysed and interpreted using the different coping strategies adopted by the LBC in overcoming their stress and challenges. The coping strategies included in the current study are cognitive decision making, direct problem solving, seeking understanding, positive cognitive restructuring, expressing feelings, physical release of emotions, distracting action, avoidant action, cognitive avoidance, problem focus support and emotion focus support. The descriptive statistics for each of the dimensions and item-wise descriptive for each dimension is discussed in the below sections. The descriptive statistics for the 11 dimensions of coping strategies are represented in Table 2.

Table 2.

Descriptive of Coping Strategies of the LBC $(n=186)$

\begin{tabular}{lll}
\hline \multicolumn{1}{c}{ Dimensions } & Mean & SD \\
\hline 1. Cognitive Decision Making & 4.06 & .67 \\
2. Direct Problem Solving & 3.90 & .70 \\
3. Seeking Understanding & 3.47 & .65 \\
4. Positive Cognitive Restructuring & 3.27 & .68 \\
5. Expressing Feelings & 2.69 & 1.11 \\
6. Physical Release of Emotions & 3.49 & .98 \\
7. Distracting Actions & 3.93 & .61 \\
8. Avoidant Actions & 3.11 & .88 \\
9. Cognitive Avoidance & 3.69 & .76 \\
10. Problem Focused Support & 3.68 & .90 \\
11. Emotion Focused Support & 3.65 & .84 \\
\hline
\end{tabular}

The results depicted that the level of cognitive decision-making (Mean=4.06, $S D=0.67$ ), direct problem solving (Mean=3.90, SD=0.70) and seeking understanding (Mean=3.47, SD=0.65) are reported as high among $\mathrm{LBC}$. Further, positive cognitive restructuring (Mean=3.27, SD=0.68), physical release of emotions (Mean=3.49, $S D=0.98$ ), distracting actions (Mean=3.93, SD=0.61), cognitive 
INTERNATIONAL JOURNAL OF ACADEMIC RESEARCH IN BUSINESS AND SOCIAL SCIENCES Vol. 9, No. 3, March, 2019, E-ISSN: 222 2-6990 @ 2019 HRMARS

avoidance (Mean=3.69, SD=0.76), problem focused support (Mean=3.68, SD=0.90) and emotion focused support are high (Mean=3.65, SD=0.84) among the LBC. Whereas the expressing feelings (Mean=2.69, SD=1.11) and avoidant actions is moderate (Mean=3.11, SD=0.88) among the middle school LBC.

The below Table 3 indicates the mean and standard deviation for the overall students' academic achievement. The average academic achievement was 51.81 whereas the standard deviation was 10.27 .

Table 3. Descriptive of Academic Achievement $(n=186)$

\begin{tabular}{lllll}
\hline Variable & Minimum & Maximum & Mean & SD \\
\hline $\begin{array}{l}\text { Academic } \\
\text { Achievement }\end{array}$ & 23.00 & 73.00 & 51.81 & 10.27 \\
\hline
\end{tabular}

To investigate the relationships among the variables correlational analysis was conducted. Table 4 displays the Pearson correlation coefficients of the variables of the study. The issue of multicollinearity among the variables was examined and the inter-correlation matrix confirmed that all the correlation values are below 0.6 and therefore the data is suitable for the multiple correlation anlaysis. Therefore, the uni-dimensionality of the variables were confirmed. The inter-correlation matrix confirmed that all the relationships are lesser than 0.7 and have shown significant positive relationships.

Table 4.

Relationships between Coping Strategies and Academic Achievement ( $n=186)$

\begin{tabular}{|c|c|c|c|c|c|c|c|c|c|c|c|c|}
\hline CS & CDM & DPS & SU & PCR & EF & PRE & DA & AvA & CA & PFS & EFS & AA \\
\hline CDM & 1 & & & & & & & & & & & \\
\hline DPS & $.639 * *$ & 1 & & & & & & & & & & \\
\hline SU & $.520 * *$ & $.594^{* *}$ & 1 & & & & & & & & & \\
\hline PCR & $.294^{* *}$ & $.364 * *$ & $.377^{* *}$ & 1 & & & & & & & & \\
\hline$E F$ & .044 & .076 & $.266^{* *}$ & $.303^{* *}$ & 1 & & & & & & & \\
\hline PRE & $.296 * *$ & $.270^{* *}$ & $.356^{* *}$ & $.175^{*}$ & $.278^{*}$ & 1 & & & & & & \\
\hline DA & $.289 * *$ & $.267^{* *}$ & $.277^{* *}$ & .097 & $.219 * *$ & $.387^{* *}$ & 1 & & & & & \\
\hline Ava & .077 & -.003 & .002 & $173^{*}$ & .083 & 0.73 & $.185^{*}$ & 1 & & & & \\
\hline CA & $.274^{* *}$ & $.322 * *$ & $.163^{*}$ & $.177^{*}$ & $.176^{*}$ & $.270 * *$ & $.247^{* *}$ & $.418^{* *}$ & 1 & & & \\
\hline PFS & $.265^{* *}$ & $.401 * *$ & $.397^{* *}$ & $.258^{* *}$ & $.311^{* *}$ & $.333^{* *}$ & $.267^{* *}$ & .087 & $\begin{array}{c}.275^{*} \\
*\end{array}$ & 1 & & \\
\hline EFS & $.177^{*}$ & $.296 * *$ & $.330 * *$ & $.211^{* *}$ & $.264^{* *}$ & $.312 * *$ & $.320 * *$ & .042 & $.165^{*}$ & $\begin{array}{c}.458^{*} \\
*\end{array}$ & 1 & \\
\hline AA & $.192 * *$ & ,296** & ,349** & $.162 * *$ & $.183^{* *}$ & $.312^{* *}$ & $.301^{* *}$ & 129 & $\begin{array}{c}.331^{*} \\
*\end{array}$ & $\begin{array}{c}.448^{*} \\
*\end{array}$ & $\begin{array}{c}.306^{*} \\
*\end{array}$ & 1 \\
\hline
\end{tabular}

$\mathrm{CDM}=$ Cognitive Decision Making; DPS=Direct Problem Solving; SU=Seeking Understanding; $P C R=$ Positive Cognitive Restructuring; $E F=$ Expressing Feelings; PRE=Physical Release of Emotions; $\mathrm{DA}=$ Distracting Actions; $\mathrm{AvA}=\mathrm{Av}$ oidant Actions; $\mathrm{CA}=$ Cognitive Avoidance; $\mathrm{PFS}=$ Problem Focused Support; EFS=Emotion Focused Support) 
$* * p<0.01, * p<0.05$

To answer the fourth research question, multiple regression analysis was examined to find out the influence of the predictor variables on the criterion variable. To ensure that the data is suitable for multiple regression analysis, the assumptions for normality, linearity, multicollinearity, autocorrelation, multivariate outliers all of which refers to various distribution of data and relationship among variables were conducted. These assumptions were tested by analysisng the Probability plot P-P plot and scatter plot. The ANOVA results show that there are significant effects between the eleven predictor variables and the criterion variable, academic achievement at $p<.001$ level. For Emotion Focused Support, Avoidant Actions, Cognitive Decision Making, Expressing Feelings, Positive Cognitive Restructuring, Physical Release of Emotions, Distracting Actions, Cognitive Avoidance, Seeking Understanding, Problem Focused Support, Direct Problem Solving, the result is significant, $F(11,174)=6.852, p<.001$. The regression model for the variables involved is represented below:

Table 5.

ANOVA Results of the Two Models for Regression Analysis

\begin{tabular}{llccccc}
\hline & Model & Sum of Squares & df & Mean Square & $\mathrm{F}$ & Sig. \\
\hline 1 & Regression & 5901.129 & 11 & 536.466 & 6.852 & $.000^{b}$ \\
& Residual & 13623.285 & 174 & 78.295 & & \\
& Total & 19524.414 & 185 & & & \\
\hline
\end{tabular}

a. Dependent Variable: academic achievement

b. Predictors: (Constant), Emotion Focused Support, Avoidant Actions, Cognitive Decision

Making, Expressing Feelings, Positive Cognitive Restructuring, Physical Release of

Emotions, Distracting Actions, Cognitive Avoidance, Seeking Understanding, Problem

Focused Support, Direct Problem Solving

Table 6 presents the correlation between the criterion variable academic achievement and the predictor variables from the regression analysis. The Table 6 indicates that model 1 is significant and shows the correlation between coping strategies and academic achievement with $r=0.550$ and $R^{2}$ value of 0.302 . This shows that $30.2 \%$ of the variance in academic achievement were caused by the eleven coping strategies. The model 2 showed that the correlation between the academic achievement and the fourteen variables is 0.625 and $R^{2}$ value of 0.390 .

Table 6.

Model Summary of Regression Analysis

\begin{tabular}{|c|c|c|c|c|c|c|c|c|c|c|}
\hline \multirow[b]{2}{*}{ Model } & \multirow[b]{2}{*}{$\mathrm{R}$} & \multirow{2}{*}{$\begin{array}{c}\text { R } \\
\text { Squar } \\
\mathrm{e}\end{array}$} & \multirow[b]{2}{*}{$\begin{array}{l}\text { Adjusted } \\
\text { R Square }\end{array}$} & \multirow{2}{*}{$\begin{array}{l}\text { Std. Error } \\
\text { of the } \\
\text { Estimate }\end{array}$} & \multicolumn{5}{|c|}{ Change Statistics } & \multirow[b]{2}{*}{$\begin{array}{l}\text { Durbin- } \\
\text { Watson }\end{array}$} \\
\hline & & & & & $\begin{array}{l}\text { R Square } \\
\text { Change }\end{array}$ & F Change & df1 & $\mathrm{df} 2$ & $\begin{array}{c}\text { Sig. F } \\
\text { Change }\end{array}$ & \\
\hline 1 & $.550^{\mathrm{a}}$ & .302 & .258 & 8.84843 & .302 & 6.852 & 11 & 174 & .000 & \\
\hline
\end{tabular}

a. Predictors: (Constant), Emotion Focused Support, Avoidant Actions, Cognitive Decision Making, Expressing Feelings, Positive Cognitive Restructuring, Physical Release of Emotions, Distracting Actions, Cognitive Avoidance, Seeking Understanding, Problem Focused Support, Direct Problem Solving c. Dependent Variable: academic achievement 
INTERNATIONAL JOURNAL OF ACADEMIC RESEARCH IN BUSINESS AND SOCIAL SCIENCES

Vol. 9, No. 3, March, 2019, E-ISSN: 222 2-6990 @ 2019 HRMARS

To explore the extent to which the predictor variables can determine the criterion variable, multiple regression was conducted. All the 11 coping strategies were entered simultaneously in the regression model. The results showed that both the models are significant. To confirm that all the variables in the study are uni-dimensional and absence of issues related to multicollinearity, Variation Inflation factor (VIF) was analysed. The acceptable range of VIF values should be between 0 and 10 and should not be very close to zero. The analysis confirmed that all the VIF values lies below 10 . This confirmed the uni-dimensionality of the independent variables considered in the present study and no issue of multicollinearity. Therefore, the data considered was suitable for regression analysis.

Table 7.

Coefficient Values for the Regression Analysis

\begin{tabular}{|c|c|c|c|c|c|c|c|c|c|}
\hline \multirow{2}{*}{ Variables } & \multicolumn{2}{|c|}{$\begin{array}{c}\text { Unstandardized } \\
\text { Coefficients }\end{array}$} & \multicolumn{2}{|c|}{$\begin{array}{c}\text { Standardized } \\
\text { Coefficients }\end{array}$} & \multirow{2}{*}{ Sig. } & \multicolumn{2}{|c|}{$\begin{array}{l}95.0 \% \text { Confidence } \\
\text { Interval for B }\end{array}$} & \multicolumn{2}{|c|}{$\begin{array}{c}\text { Collinearity } \\
\text { Statistics }\end{array}$} \\
\hline & B & SE & Beta & $\mathrm{t}$ & & $\begin{array}{l}\text { Lower } \\
\text { Bound }\end{array}$ & $\begin{array}{l}\text { Upper } \\
\text { Bound }\end{array}$ & Tolerance & VIF \\
\hline Const. & 15.183 & 5.842 & & 2.599 & .010 & 3.653 & 26.713 & & \\
\hline CDM & -1.708 & 1.343 & -.111 & -1.272 & .205 & -4.359 & .942 & .528 & 1.893 \\
\hline DPS & .309 & 1.419 & .021 & .217 & .828 & -2.492 & 3.109 & .425 & 2.354 \\
\hline SU & 3.220 & 1.382 & .205 & 2.329 & $.021^{*}$ & .492 & 5.948 & .519 & 1.928 \\
\hline PCR & -.194 & 1.115 & -.013 & -.174 & .862 & -2.395 & 2.008 & .734 & 1.363 \\
\hline $\mathrm{EF}$ & -.311 & .676 & -.034 & -.460 & .646 & -1.646 & 1.024 & .754 & 1.326 \\
\hline PRE & .618 & .780 & .059 & .792 & .429 & -.922 & 2.158 & .719 & 1.392 \\
\hline DA & 2.267 & 1.241 & .135 & 1.827 & .069 & -.182 & 4.715 & .737 & 1.357 \\
\hline AA & .051 & .845 & .004 & .060 & .952 & -1.617 & 1.719 & .757 & 1.322 \\
\hline CA & 2.673 & 1.045 & .198 & 2.557 & $.011 *$ & .610 & 4.735 & .668 & 1.498 \\
\hline PFS & 3.617 & 1.039 & .317 & 3.481 & $.000 * *$ & 1.566 & 5.667 & .485 & 2.063 \\
\hline EFS & -.478 & 1.057 & -.039 & -.452 & .651 & -2.565 & 1.608 & .531 & 1.883 \\
\hline
\end{tabular}

$\mathrm{CDM}=$ Cognitive Decision Making; DPS=Direct Problem Solving; SU=Seeking Understanding;

$P C R=$ Positive Cognitive Restructuring; $E F=$ Expressing Feelings; PRE=Physical Release of Emotions;

$\mathrm{DA}=$ Distracting Actions; $\mathrm{AvA}=$ Avoidant Actions; $\mathrm{CA}=$ Cognitive Avoidance;

PFS=Problem Focused Support; EFS=Emotion Focused Support)

$* p<.05, * * p<.001 * *$

a. Dependent Variable: academic achievement

When the 11 different coping strategies were entered, the results indicated that the highest beta was recorded for Problem Focussed Support (PFS), followed by seeking Understanding (SU) and Cognitive avoidance (CA) and were significant. Among the 11 coping strategies entered in the model, the results concluded that problem focussed support $(\beta=.317 ; \mathrm{t}=3.481, \mathrm{p}<0.000)$ have a stronger unique contribution in explaining the academic achievement of the LBC. The other significant coping strategies that predicts academic achievement is seeking understanding $(\beta=.205 ; t=2.329, p<0.021)$ which was followed by cognitive avoidance $(\beta=.198 ; t=2.557, p<0.05)$. On the whole, Model 1 can explain $30.2 \%$ of the variance of academic achievement of the $L B C$ and problem focussed support is the most significant predictor that contributes to the academic achievement of the LBC. 


\section{Discussion}

The results confirmed that all the 11 coping strategies were moderately used by the LBC at varied degrees and the highest mean was reported for Cognitive decision making while the lowest mean was reported for restructuring expression. The LBC have better cognitive decision making which concluded that LBC are able to plan and think about their problems and could decide the better choices that would improve their life. Cognitive decision making involves other subskills and the study confirmed that middle school LBC are able to plan, recognize problems, decide an action, predict interactions, propose solutions, and anticipate future consequences and reactions. Schmalzbauer (2004) claimed that LBC need to have better planning skills which is essentially the steps for actions and relevant strategies, thinking about the action steps and how well it solves their problems. Epstein (2003) also agreed on the view that planning is essential in making choices. The chosen choice is with the purpose of intention to achieve a specific objective or solve a problem.

The descriptive analysis of direct problem solving concluded high level of mean and concluded that LBC have taken necessary efforts to change their problem situation and make their life better. This implies that LBC were able to change himself, herself, or the environment for a better life. Navarez \& Diaz (2017) reported similar findings, which proved that when children used planning as a coping mechanism they tried to come with certain approaches or strategy about what to do. They are able to identify the plausible steps and interventions that could help them in difficult times. Furthermore, they further reported that active coping is a potential coping mechanism where the children try to focus on their efforts on doing something about their stressful situation and take the ownership of direct actions to get solve the problem. Active coping provides avenue for the LBC to function well and move forward in life (Navarez \& Diaz, 2017). Carver, Scheier, and Weintraub (1989) showed similar findings that LBC need to take active steps to eliminate or avoid the stress by increasing one's efforts, initiating direct action and trying to cope and execute actions in a stepwise manner. Thus, it helps the LCB to perform their tasks and responsibilities although they are facing depressing or painful situation. This showed that LBC are capable of performing certain actions and not just limit themselves to thinking about their problems.

With regards to seeking understanding, LBC have better meaning of the problematic situations and are able to derive meaning of their life situation. They are capable of putting in cognitive efforts to understand and to find meaning of their stressful circumstance. Findings from Navarez \& Diaz (2017) showed that left behind children of overseas Filipino workers had the ability to accept the reality, able to learn to live with it and had better acceptance as a coping mechanism. Furthermore, according to Lazarus (2000) proposed that people view stress in two ways, either challenging or threatening. To overcome the stressful life situations individuals should adopt coping skills. Therefore, how left behind children encounter the stressful life events and make meaning out the situation depend on their coping skills. Literature review indicated that acceptance, as a coping mechanism is more constructive for LBC compared to NLBC. When LBC tend to accept reality, they are able to deal with disappointments and hindrances and feel satisfied (Stoeber \& Janssen, 2011).

The high level of positive cognitive restructuring concluded that LBC are able to think about the situation in a more positive way and have high level of acceptance of reality and life as a whole. LBC considered the problem in an optimistic approach and have thoughts that minimize the problem or the consequences of the problem. The study done by Navarez \& Diaz (2017) also produce similar 
results in which they found that in a sample of Philippine Students' Left-Behind Children by Overseas Filipino Worker Parents, the students used positive reframing as a coping mechanism, and they tried to see their difficulties in a positive way as well they added meaning to their problem situation. In the similar line, Dempsey (2010) further concluded that adolescents who adopt positive reframing coping strategy, have more positive reactions and outcomes after experiencing intense victimization. The study concluded that LBC are able to cope up the stress by expressing feelings. EF involves the overt expression of feelings either by an action to express feelings, or a verbal expression of feelings or simply an overt release of emotion. This finding contradicts with the findings from Graham et al. (2012) study. Graham et al. (2012) stated in their study on Indonesian and Filipino LBC do not express feelings much when they are under stress. Their response to the stress was not telling anyone what they feel and kept the feeling to themselves as a secret. This shows that there is a slight difference on the LCB's response between countries in terms of expressing their feelings when they are under stress.

With respect to physical release of emotion as coping strategy adopted by $L B C$, refers to the efforts to physically work off feelings by playing games, sports or physical exercise. This concluded that LBC do engage in physical activities and this helped them to cope up with the stressors. Khabiri (2009) further supported that when children involve in active physical exercises, it helps them to release all the stress that they had during the exercises. Thus, this bring a positive effect to their mental health as it lower down the mental stress and depression that they had. The current study showed that LBC uses distraction avoidance strategy to cope well. Mates \& Allison (1992) reported similar findings that confirmed that most children cope with the stress through diversionary responses such as involving in sports, listening to music or playing an instrument. A participant in the study said that when he plays a musical instrument such as drum, he would bang the drums very hard as a source of fighting with the stress. However, Mates and Allison (2012) claimed in the study that these diversionary responses are just a temporary solution in coping with the stress, as they do not deal with the underlying source of problem. This shows that although these distracting activities are good in helping LCB cope with stress, the effect is only temporary.

Many researchers claimed that social support assist children to cope with stress (Schwarzer \& Leppin, 1989) and derive meaning for stressful life experiences (Brannon \& Feist, 2009). They do it by trying to get advice from someone about what to do, learn more about the situation, and ask people who have had similar experiences with them. Meanwhile, Ozbay et al., (2007) viewed that instrumental support needs to be offered to individuals through social linkages such as groups, organizations and the community as a whole.

The descriptive analysis for emotion focus support(EFS) showed that LBC have better EFS. They received good support from other people in listening to their feelings and problems and this had helped them to reduce their distress. Findings from this study agreed with few other studies. Navarez, \& Diaz (2017) reported that when LBC used emotional support as a coping mechanism, they received emotional support from family and friends or relatives. The LBC discussed their feelings and expressed their emotional need. Furthermore, Burleson (2003) pointed out that children need care and sensitive support during the downside feeling of LBC. Having someone to trust and rely on is crucial for better relationship. This prevents the children in developing disruptive emotional outbursts and depression. Therefore, emotional support is helping to lift someone to higher ground 
and an individual can see their way through the difficulty. This emphasizes how vital the emotion focus support is in helping LCB to go through difficulty in life.

The descriptive analysis of the academic achievement of the LBC showed average academic achievement. The regression analysis concluded that $30.2 \%$ of the variance of academic achievement of the LBC and problem focussed support is the most significant predictor followed by cognitive avoidance and seeking understanding. The findings could be attributed various factors which involves both psychological and home factors. Children with migrant parents have increased labour burdens, affecting the amount of time and effort that they could spend on their schoolwork and studies at home. Moreover, they lack a family tutor to help them in any areas of misunderstanding or doubt in their academics. Thus, academic performance of left-behind children lag behind in comparison to their own previous performance in the periods when their parents had not yet migrated. Earlier studies which compared LBC and NLBC) non left-behind children) have identified that no significant difference between left-behind children and their peers in the aspect of academic interest and academic achievement, however, there exist noteworthy differences in the academic supervision and home environment. Despite the difficulties that the children face in the absence of their parents, studies have showed better performance of the LBC in the absence of their parents. Studies conducted in Brazil, Philippines, Mexico and other countries have showed that when parents are away, the time available for the children to engage is studies is better and the children classroom performance was improved compared to when stay with their parents (Acosta, 2006; Hanson \& woodruff, 2003). This affirmative influence is due to successful coping skills that allow children to think, decide and make better changes in his/her life. This proved that the effectiveness of coping among the LBC is determined by the nature of stress, type of individual, and the environments surrounding it (Lee et al., 2009).

Besides, study done by Bakker, Elings-Pels and Reis (2009) also pointed out that children are significantly affected by migration of their parents and the children are likely to develop depression, low self-esteem which acts as precursors of other disruptive behaviours. Furthermore, these children lose the right to education, poor performance and interruptions in schooling. The results concluded that LBC are able to able to make different choices and predict its future consequences, plan or think in certain ways to cope up with the stressful situations and handle it effectively.

The regression analysis concluded that among the 11 different coping strategies only three coping strategies were significant. Problem focussed support (PFS) was identified as the most significant predictor of academic achievement of the LBC. The second significant predictor was seeking understanding (SU) which was followed by cognitive avoidance (CA). The findings highlighted the necessity of the problem focussed support to be available for the LBC to improve their coping and achievement. Therefore, the study suggests the importance of counselling services at the school, where appropriate psychological support is extended to the LBC. Roberts \& Crawford (2008) concluded similar findings that present generation of children need tangible support as they face varied challenges that extend beyond their cognitive domain. The study recommends that the government and community could consider appropriate intervention and support to be offered to the care takers of the LBC. This afford the improved support for the LBC at both school and home. Seeking understanding is identified as the significant predictor, which confirms that LBC attempt to broaden their understanding about their life by finding the meaning of their problems. This urge the 
need for social constructivist approach in the construction of knowledge and understanding of the LBC in dealing their life situations. Social constructivist approach (Vygotsky,1978) claimed that knowledge is co-constructed and therefore, LBC need to be allowed to discuss their problems and needs to their parents, care-takers, teachers and peers who could extend support for the LBC. The study further confirmed that LBC try to cope their stress by using cognitive avoidance strategy. Therefore, activities such as discussions on building positive future orientation, seeking efficient social support, and emotion regulation should also be included in the intervention programme as they further help LBC in enhancing their coping and better academic achievement.

\section{Conclusion}

In conclusion, the findings of the current study provide empirical evidence for the coping strategies adopted by left-behind children in overcoming their stressful life events and the effect of their coping in academic achievement. Among the 11 coping strategies that were investigated in the study, only 3 coping strategies, problem focussed support; cognitive avoidance and seeking understanding were identified as the significant predictors of academic achievement. Therefore, the study urge the educational stakeholders to provide psychological support for the LBC at home, school and community. The study recommends the need for social support and counselling services at school, which will allow the left-behind children understanding their life situation.

Correspondence: Priyadarshini Muthukrishnan, Faculty of Education, SEGi University, Kota Damansara, Selangor, Malaysia

Email: priyakrishnan.mail@gmail.com

\section{References}

Acosta, P. (2006). Labor Supply, School Attendance, and Remittances from International Migration: The Case of El Salvador. World Bank Policy Research Working Paper 3903, The World Bank, Washington, DC.

Asis, M. (2006). Living with migration: experiences of children left-behind in Philippines. Asia Population Studies (2), 45-67.

Ayers, T. (1991). A dispositional and situational assessment of children's coping: Testing alternative theoretical models. Unpublished doctoral dissertation, Arizona State University.

Bakker, C., Elings-Pels, M., \& Reis, M. (2009). The Impact of Migration on Children in the Caribbean. Retrieved from http://www.unicef.org/easterncaribbean/Impact_of_Migration_Paper.pdf

Brannon, L., \& J., Feist, (2009). Personal coping strategies. Health psychology: An Introduction to behaviour and health (7th ed.), Wadsworth: Cengage Learning

Burleson, B. R. (2003), The experience and effects of emotional support: What the study of cultural and gender differences can tell us about close relationships, emotion, and interpersonal communication. Personal Relationships, 10, 1-23

Cao, C. (2007). Analyzing study performance of rural left-behind children. Education Exploration and Practice, 5, 73-74 (original in Chinese).

Carver, C.S., Scheier, M.F., \& Weintraub, J.K. (1989). Assessing coping strategies: A theoretically based approach. Journal of Personality and Social Psychology, 56, 267-283. 
INTERNATIONAL JOURNAL OF ACADEMIC RESEARCH IN BUSINESS AND SOCIAL SCIENCES

Vol. 9, No. 3, March, 2019, E-ISSN: 222 2-6990 ¿ 2019 HRMARS

Dempsey, M. (2010). Negative coping as mediator in the relation between violence and outcomes: Inner city African American Youth. American Journal of Orthopsychiatry, 72(1), 103-109. DOI: 10.1037/0002-9432.72.1.102

Graham, E., Jordan, L., Yeoh, B., Lam, T., \& Asis, M. (2012). Transnational families and the family nexus: perspectives of Indonesian and Filipino children left behind by migrant parent (s). Environment and Planning A. 44(4) $793-815$

Epstein, S. (2003). Cognitive-experiential self-theory of personality. DOI:10.1002/0471264385.wei0507

Fan, F., Su. L,, Gill. MK \& Birmaher. B. (2010). Emotional and behavior problems of Chinese leftbehind children: a preliminary study. Social Psychiatry and Psychiatric Epidemiology, 45(6), 655-664. DOI: 10.1007/s00127-009-0107-4.

Folkman, S., \& Moskowitz, J. T. (2004). Coping Pitfalls and Promise. Annual Review of Psychology, $55,745-774$.

Gao, Y. et al., (2010). The impact of parental migration on health status and health behavior among left behind adolescent school children in China. BMC Public Health, 10.56

Hanson, G. H., \& Woodruff. C. (2003). Emigration and Educational Attainment in Mexico. University of California, San Diego, Mimeo.

Khabiri, M. (2009). The effect of stress, depression and anxiety on postsecondary students strategies. Journal of College Students Development. 39(1), 11-22.

Koo, A. H. (2014). The doubly disadvantaged: How return migrant students fail to access and deploy capitals for academic success in rural schools. Sociology, 4, 795-811.

Lazarus, R. S. (2000). Toward better research on stress and coping. American Psychologist, 55, 665-673.

Lee, Y.K., Baek, K.W., Yun, K.W., Lim, W., \& Lim, W. (2009). The association of coping mechanisms with arterial stiffness in Hwa-Byung patients. Psychiatry Investigation. 6(4), 241-244.

Lv, S. (2006). Research on the issue of left-behind children in rural China. Chinese Women"s Movement, 6, 19-25 (original in Chinese).

Marshall, S. et al. (2013). Non-suicidal self-injury and depressive symptoms during middle adolescence: A longitudinal analysis. J. Youth Adolescent, 42, 1234-1242. DOI: 10.1007/s10964-013-9919-3

Mates, D., \& Allison, K. R. (1992). Sources of stress and coping responses of high school students. Adolescence, 27(106), 461-474.

McLanahan, S. S. (1994). Growing up with a single parent: What hurts, what helps. Cambridge, MA: Harvard University Press.

Montague, M., Enders, C., \& Castro, M. (2005). Academic and behavioral outcomes for students at risk for emotional and behavioral disorders. Behavioral Disorders. 31. 84-94.

Navarez, J., \& Diaz, K. R. (2017). Coping mechanisms of Philippine students' left behind by OFW parents. Slongan, 3(1), 91-102.

Ozbay, F., Johnson, D. C., Dimoulas, E., Morgan, C. A., Charney, D., \& Southwick, S. (2007). Social support and resilience to stress: from neurobiology to clinical practice. Psychiatry 4,35-40. 
Roberts, S. K., \& Crawford, P. A. (2008) Literature to Help Children Cope with Family Stressors. Young Children, 16, 12-18.

Schmalzbauer, L. (2004) 'Searching for wages and mothering from afar: the case of Honduran transnational families', Journal of Marriage and Family, 66, 1317-31.

Schwarzer, R., \& Leppin, A. (1989). Social support and health: A meta-analysis. Psychology \& Health, 3(1), 1-15.

Shen M, G. J. (2015). Parental migration patterns and risk of depression and anxiety disorder among rural children aged 10-18 years in China: a cross-sectional study. BMJ Open.

Stoeber, J., \& Janssen, D. P. (2011). Perfectionism and coping with daily failures: Positive reframing helps achieve satisfaction at the end of the day. Anxiety, Stress, \& Coping, 24(5), 477-497.

UNICEF. (2014). Children in China: an atlas of social indicators. Beijing: United Nations Children's Fund.

Valtolina, G. Chiara. C. (2012). Psychological Well-Being, Family Relations and Developmental Issues of Children Left Behind. Psychological Reports, 111, 905-928. DOI: 10.2466/21.10.17.PR0.111.6.905-928

Vygotsky, L. S. (1978). Mind in society: The development of higher psychological processes. Cambridge, MA: Harvard University Press.

Wen, M. (2008). The effect of family structure on children"s health and well-being: Evidence from the 1999 National Survey of America"s Families. Journal of Family Issues, 29, 1492-1519.

Ye, J. Z., \& Murray, J. (2005). Left-behind children in rural China. Beijing, China: Social Science Academic Press. 